\title{
Optimasi Bandwidth Menggunakan Metode Peer Connection pada Dinas Lingkungan Hidup Pematangsiantar
}

\author{
Jose Andreas Tampubolon ${ }^{1 凶)}$, Suhada $^{2}$, M Safii ${ }^{3}$, Poningsih ${ }^{4}$, Bahrudi Efendi Damanik ${ }^{5}$ \\ 1) Program Studi Teknik Informatika, STIKOM Tunas Bangsa, Pematangsiantar, Indonesia \\ 1) josetampubolon@gmail.com
}

\author{
2)344)5) STIKOM Tunas Bangsa, Pematangsiantar, Indonesia \\ 2) suhada.atb@gmail. com \\ ${ }^{3)}$ m. safiidamiktunasbangsa.ac.id \\ 4) poningsiheamiktunasbangsa.ac.id \\ 5) bahrudiefendi lgmail. com
}

\begin{abstract}
The purpose of this study is to provide good Quality of Service for all internet users in a network by managing bandwidth with the Peer Connection Queue (PCQ) method using Queue Tree. By applying the Peer Connection Queue (PCQ) method using a Queue Tree, every user who accesses the internet will get an even bandwidth allocation. Testing using a Mikrotik RouterBoard with several computers connected via wired and several devices connected via a wireless network. The results show that bandwidth management using the PCQ method using Queue Tree gives better results than without using PCQ because by using PCQ all users who are members of one network get an equal bandwidth allocation between one another so that users feel fair. Which means that the Quality of Service provided by the network provider is very good.
\end{abstract}

Keywords-Bandwidth, Queue Tree, Quality of Service, Peer Connection Queue, Mikrotik

Intisari- Tujuan penelitian ini adalah untuk memberikan Quality of Service yang baik bagi seluruh pengguna internet dalam suatu jaringan dengan cara memanajemen bandwidth dengan metode Peer Connection Queue (PCQ) menggunakan Queue Tree. Dengan menerapkan metode Peer Connection Queue (PCQ) menggunakan Queue Tree, maka setiap user yang mengakses internet akan mendapatkan alokasi bandwidth yang merata. Pengujian menggunakan Mikrotik RouterBoard dengan beberapa komputer yang disambungkan via wired dan beberapa perangkat yang disambungkan melalui jaringan wireless. Hasil penelitian menunjukan bahwa manajemen bandwidth dengan metode PCQ menggunakan Queue Tree memberikan hasil yang lebih baik dibandingkan tanpa menggunakan PCQ sebab dengan menggunakan PCQ semua user yang tergabung dalam satu jaringan mendapatkan alokasi bandwidth yang sama rata antara satu dan yang lain sehingga pengguna merasa adil. Yang mana artinya Quality of Service yang diberikan oleh penyedia jaringan sudah sangat baik.

\section{PENDAHULUAN}

Jaringan internet memberi dampak yang besar bagi manusia dalam meringankan pekerjaan yang mereka lakukan. Melalui teknologi juga dapat mempercepat pekerjaan atau dalam kata lain dapat mempersingkat waktu dalam melakukan pekerjaan. Selain itu teknologi dapat membuat percakapan antar pribadi menjadi dekat meskipun jarak diantara pribadi tersebut sangat jauh, lalu melalui teknologi juga dapat menjadi sarana mendapatkan informasi dan berbagai informasi [1].

Berdasarkan pengamatan yang dilakukan oleh penulis di Dinas Lingkungan Hidup di Pematangsiantar masih terjadi lambatnya koneksi internet sehingga pekerjaan yang dilakukan oleh karyawan-karyawan mengalami terkendala sehingga performa dinas lingkungan hidup menjadi menurun. Masalah ini terjadi dikarenakan masing-masing karyawan menggunakan jaringan internet yang sama, sehingga masing-masing komputer yang digunakan saling tarik menarik jaringan, tarik menarik jaringan tersebut membuat koneksi internet melambat.

Berdasarkan latar belakang di atas, maka dapat dirumuskan masalah yang dibahas pada penelitian ini ialah belum terbagi ratanya koneksi internet pada Dinas Lingkungan Hidup sehingga diperlukan solusi untuk mengatasi masalah penggunaan koneksi internet tersebut dengan menerapkan manajemen Bandwidth pada sistem local area network menggunakan Metode PCQ (Peer Connection Queue).

Pada penelitian terdahulu yang di lakukan oleh di mana koneksi internet di salah satu sekolah tinggi yang berada di Bancak mengalami lambatnya koneksi internet dikarenakan dalam satu penggunaaan jaringan internet banyak di gunakan seperti dalam ruangan laboratorium komputer, tata usaha, administrasi, dan proses kegiatan pembelajaran, masalah lambatnya jaringan koneksi internet dapat diatasi dengan memanajemen jaringan internet dengan menggunakan metode PCQ [2]. 


\section{Metodologi Penelitian}

\section{A. Rancangan Penelitian}

Rancangan penelitian ini pertama kali penulis melakukan pengamatan selanjutnya mengumpulkan data setelah itu, data tersebut akan diolah melalui proses analisa bandwith yang digunakan dalam sehari kemudian membuat rancangan topologi yang akan dibangun agar dapat mengimplementasikan manajemen bandwidth dengan metode PCQ menggunakan Queue Tree. Rancangan penelitian dapat dilihat pada gambar 1 .

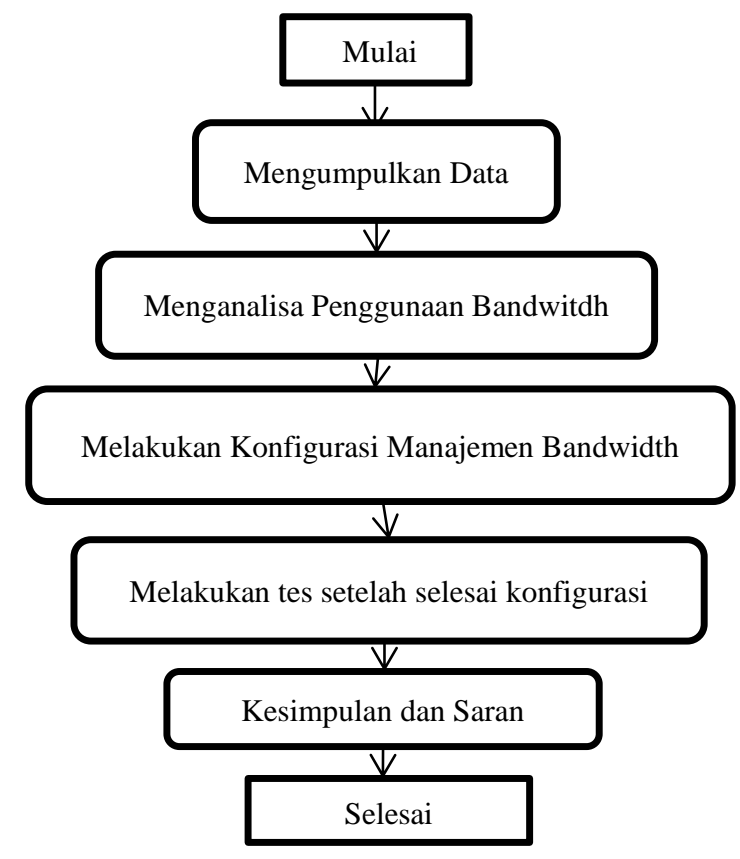

Gambar 1. Rancangan Penelitian

\section{B. Prosedur Pengumpulan Data}

Dalam melakukan penelitian ada beberapa prosedur dalam penumpulan data, yaitu:

1. Penelitian Kepustakaan (Library Research) yaitu memanfaatkan perpustakaan, buku, prosiding atau jurnal sebagai media untuk bahan referensi dalam menentukan parameter yang digunakan dalam penelitian.

2. Sumber data penelitian diambil dari Kantor Dinas Lingkungan Hidup yaitu penggunaan bandwidth selama 1 bulan.

\section{Manajemen Bandwidth}

Manajemen bandwidth ialah suatu usaha yang dilakukan untuk mengkontrol besar atau kecilnya jumlah volume data yang dikeluarkan dalam satuan detik guna untuk mempercepat jaringan yang ada pada komputer [3]. Ada beberapa metode dalam pengaplikasian bandwidth manajemen yaitu dengan menggunakan proxy server, qos ataupun traffic shapping, pembatasan bandwidth (limiter).

1. Proxy server: adalah sebuah server atau program komputer yang berperan sebagai penghubung antara suatu komputer dengan jaringan internet. Proxy server menjadi perantara antara jaringan lokal dan jaringan internet [4].

2. QOS (Quality of Service) : ialah pengukuran performansi dan tingkat kualitas pada jaringan untuk menyediakan tingkat jaminan performansi pada layanan yang berbeda [5].
3. Pembatasan bandwidth (Limiter) ialah suatu metode yang digunakan untuk membatasi jumlah volume atau data yang dikeluarkan salah satu metode ini ialah PCQ (Peer Connection Queue).

\section{PCQ (Peer Connection Queue)}

Peer connection queue (PCQ) ialah sebuah metode yang dilakukan untuk membagi bandwidth dengan cara membagi sesuai dengan subclass atau subqueue pada masing-masing user [6]. Metode pembagian bandwidth dengan menggunakan metode ini merupakan metode yang paling sederhana dan mudah digunakan untuk membagi bandwidth ke-semua komputer [7].

Cara kerja PCQ adalah dengan menambahkan sub-queue, berdasar classifier tertentu [8]. Berikut gambar 2 cara kerja PCQ dengan parameter PCQ-Rate $=0$.

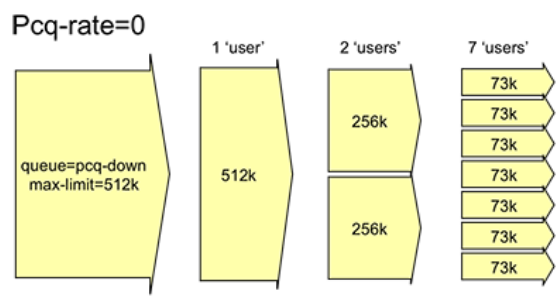

Gambar 2. Cara Kerja PCQ

\section{E. Pemodelan Metode}

Berdasarkan referensi definisi sejumlah model pengembangan sistem yang ada, dalam penelitian ini penulis menggunakan metode pengembangan sistem Network Development Life Cycle (NDLC). NDLC merupakan model yang mendefinisikan siklus proses perancangan atau pengembangan suatu sistem jaringan komputer, NDLC mempunyai elemen yang mendefinisikan fase, tahapan, langkah atau mekanisme proses spesifik [9]

Pemodelan metode dapat dilihat pada gambar 3.

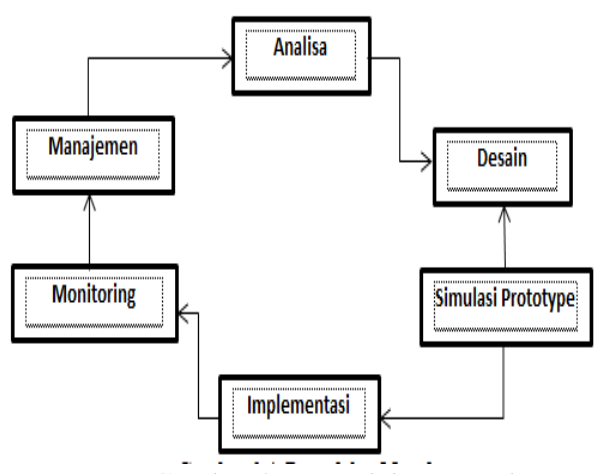

Gambar 3. Pemodelan Metode

\section{HASIL DAN PEMBAHASAN}

Pada bagian ini adalah hasil dalam penelitian terhadap perancangan berdasarkan hasil analisis. Tujuan penerapan rancangan metode Queue Type PCQ pada Dinas Lingkungan Hidup Pematangsiantar adalah untuk mengimplementasikan rancangan yang telah dibuat untuk mempermudah pengguna dalam menggunakan internet. Pengujian rancangan jaringan ini menjelaskan tentang pembagian bandwidth menggunakan perangkat keras dan perangkat lunak yang sudah disiapkan. 


\section{A. Implementasi Jaringan Wifi}

Rancangan yang digunakan dalam implementasi wifi pada Dinas Lingkungan Hidup Pematangsiantar yaitu menggunakan router board RB750r2 dan dilakukan pada 2 laptop, modem $3 G$, dan $H u b$. Tahap pertama yaitu menghubungkan modem $3 G$ ke laptop, dengan modem $3 G$ sebagai pusat internet, kemudian menghubungkan laptop (1) yang sudah terhubung internet ke mikrotik RB750r2, kemudian RB750r2 yang dihubungkan pada $H u b$ dan menghubungkan laptop (2) ke mikrotik menggunakan kabel UTP untuk melakukan konfigurasi mikrotik. Pada penelitian ini aplikasi yang digunakan untuk mengkonfigurasi mikrotik yaitu aplikasi winbox dengan menggunakan aplikasi tersebut pada laptop.

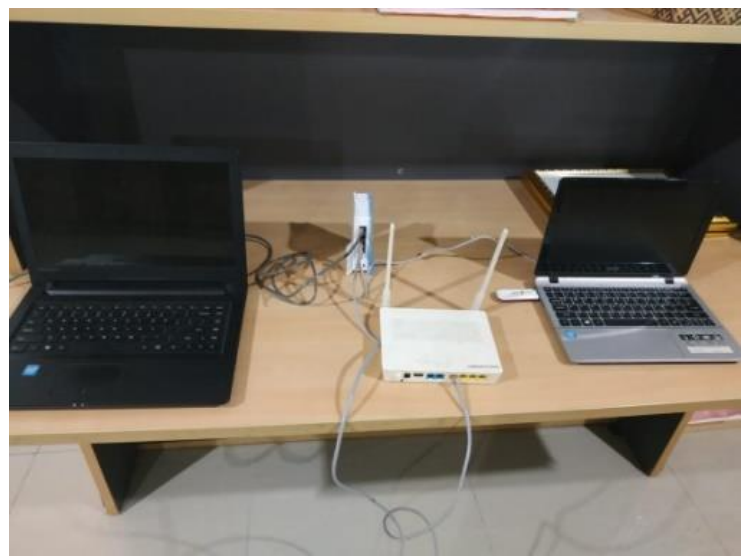

Gambar 4. Perangkat Keras

\section{B. Konfigurasi Mikrotik}

Konfigurasi mikrotik menggunakan aplikasi winbox dalam penerapan pemabagian bandwith internet menggunakan metode Queue Type $P C Q$ pada Dinas Lingkungan Hidup Pematangsiantar dan sistem operasi mikrotik. Dengan menggunakan router board, maka sistem operasi mikrotik secara otomatis sudah terinstal. Selanjutnya konfigurasi mikrotik dilakukan dengan menggunakan aplikasi Winbox. Berikut tampilan konfigurasi mikrotik menggunakan winbox.

Berikut konfigurasi mikrotik dengan menggunakan winbox. Setting Interface Mikrotik dengan membuka menu interface maka akan tampil pada gambar 5 berikut:

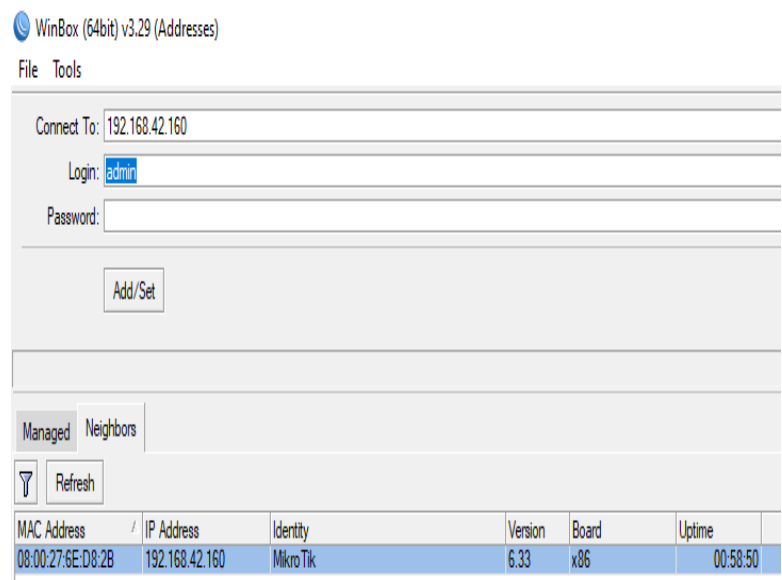

Gambar 5. Tampilan Awal Winbox

Setelah masuk ke menu interface klik MAC Addresss yang sudah terdaftar di tampilan winbox tersebut, kemudian klik connect maka akan tampil seperti gambar 6 sebagai berikut:
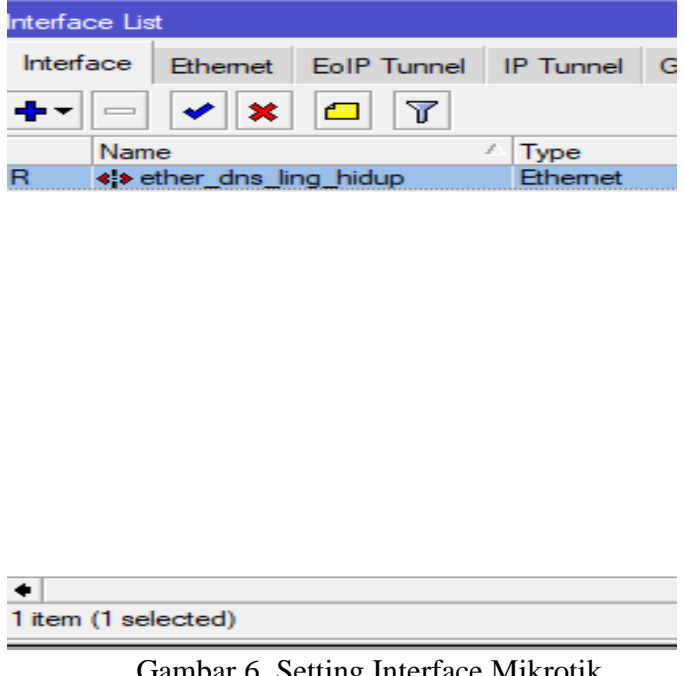

Gambar 6. Setting Interface Mikrotik

Selanjutnya ubah nama interface Mikrotik menjadi seperti gambar 7 dibawah ini.

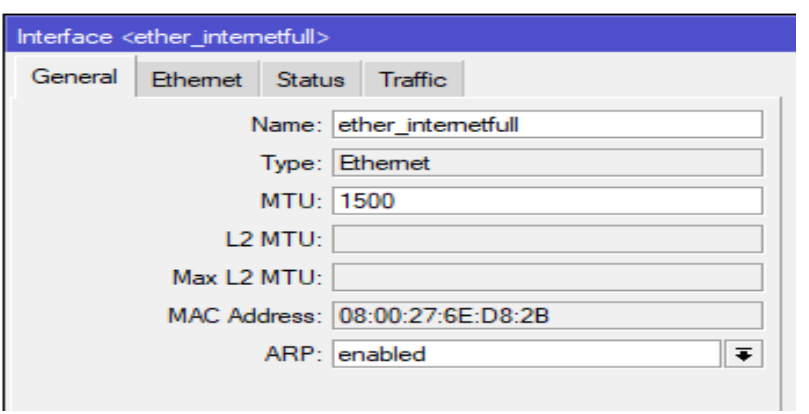

Gambar 7. Tampilan Interface Mirkotik

Maka dapat dilihat seperti gambar diatas setting nama Interface Mikrotik. Ether_Internet Dinas Lingkungan Hidup Pematangsiantar Kemudian Setting IP Address Mikrotik. Dengan IP Addresss seperti berikut ini: IP Addresss Modem=192.168.42.160/24 Di Mikrotik: IP Addresss Eternet1internet $=192.168 .10 .1 / 24$. Dapat dilihat pada gambar 8 dibawah ini:

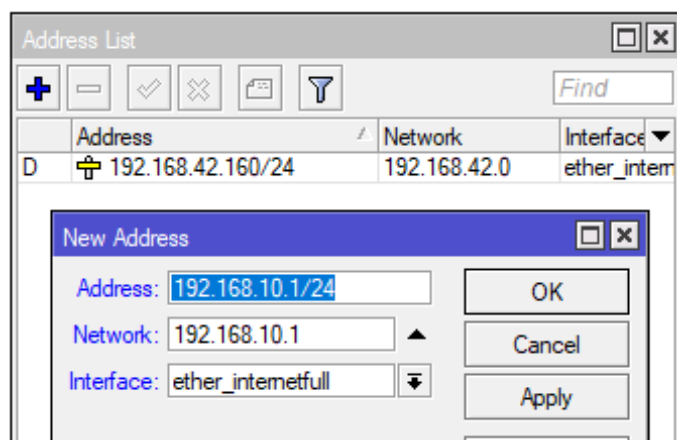

Gambar 8. Tampilan Interface IP Address

Setelah IP Addresss mikrotik diubah, selanjutnya berikan DNS server yang akan di isi dengan IP Addresss yang berasal dari modem. Dapat dilihat pada gambar 9 dibawah ini: 


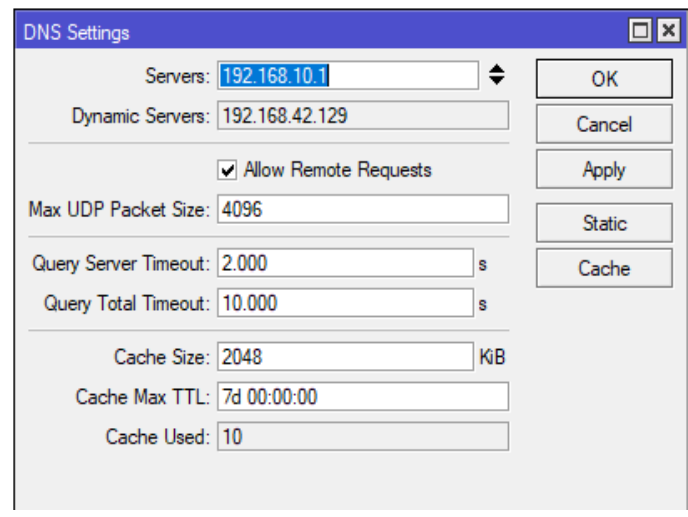

Gambar 9. Tampilan DNS Server

Setelah DNS Server sudah di konfigurasi lanjut ke konfigurasi Routers, memberikan Default Gateway dengan IP Addresss Modem. Dapat dilihat pada gambar 10 dibawah ini:

Route $\langle 0.0 .0 .0 / 0>$
General $\mid$ Attributes
Dst. Address: $0.0 .0 .0 / 0$
Gateway: 192.168 .10 .12
Check Gateway:

Gambar 10. Tampilan Routers

Setelah proses konfigurasi Routers selesai lakukan pengujian pada modem, modem memiliki IPAddress 192.168.10.1 seperti pada gambar 11 dibawah ini:

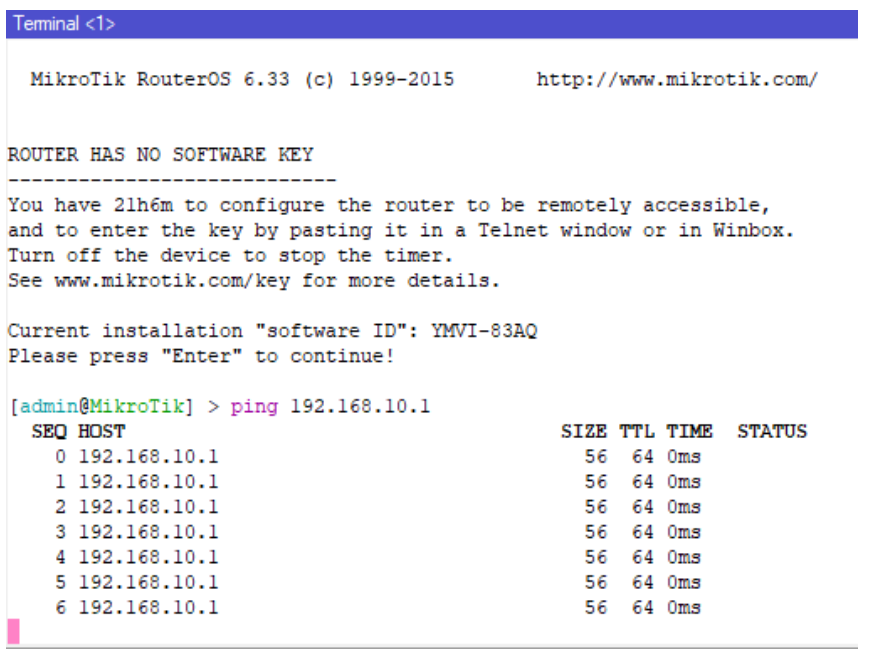

\section{Gambar 11. Tampilan Ping Modem}

Selanjutnya konfigurasi agar Client terhubung ke internet, yaitu dengan cara mengkonfigurasi Firewall NAT. Seperti pada gambar 12 dibawah ini:

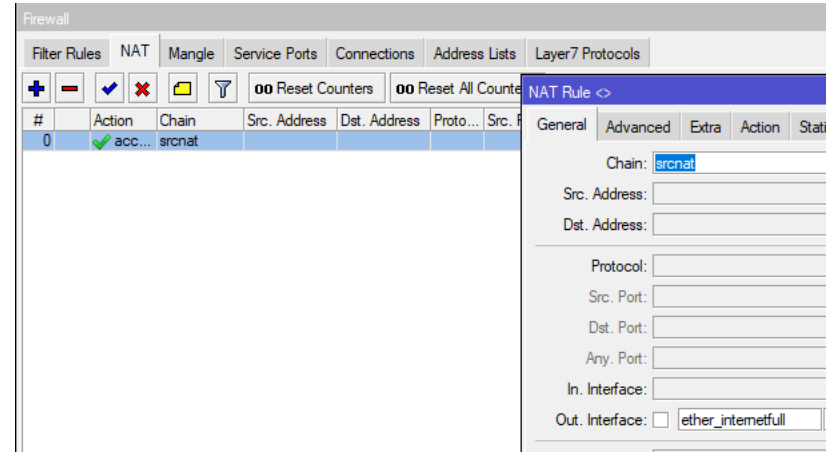

Gambar 12. Tampilan Firewall NAT

Selanjutnya membuat IP Pool agar client tidak mengisi IP Addresss secara manual. Dapat dilihat pada gambar 13 dibawah ini:

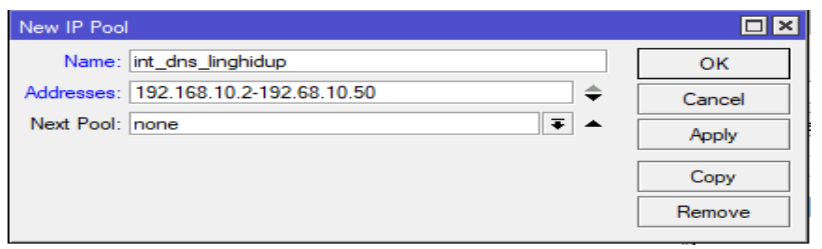

Gambar 13. Tampilan IP Pool

Setelah konfigurasi IP Pool selesai dilakukan selanjutnya konfigurasi Network yang ada di DHCP server seperti pada gambar 14 dibawah ini:

\begin{tabular}{|c|c|c|c|c|c|c|c|}
\hline JHCP Senve & & & & & & & 回 \\
\hline DHCP Netwoks & Leases Options & Option Sets Aler & & & & & \\
\hline$t=0 \nabla$ & & & DHCP Netwook 19 & $22168.10 .0 / 24$ & & प्र & Find \\
\hline Address & $1 /$ Gateway & DNS Severs & Address: & $1921.168 .100 / 24$ & & OK & $\checkmark$ \\
\hline & & & Gateway: & 192.168.10.1 & $\hat{v}$ & Cancel & \\
\hline & & & Netmask: & & $\Delta$ & Anoly & \\
\hline & & & DNS Severs: & 192.168.10.1 & 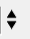 & & \\
\hline & & & Domain: & & 1 & Comment & \\
\hline & & & WINS Servers: & & $\Delta$ & Copy & \\
\hline & & & NTP Severs: & & $\Delta$ & Remove & \\
\hline
\end{tabular}

Gambar 14. Tampilan DHCP Network

Langkah berikutnya melakukan tahapan konfigurasi $D H C P$ server dapat dilihat pada gambar 15 berikut.

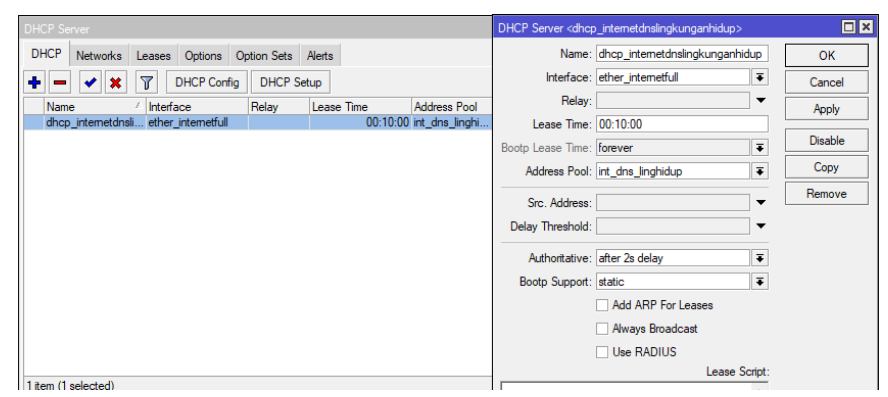

Gambar 15. Tampilan DHCP Server 
Konfigurasi $D H C P$ Server bertujuan untuk memberikan alamat modemnya yang ditujukan ke Ethernet LAN Hub, agar Ethernet LAN Hub dapat terhubung ke Internet.

Konfigurasi $D H C P$ server sudah di buat, Hub sudah bisa terhubung ke internet. Selanjutnya dilakukan test dengan Ping google.com. Dapat dilihat pada gambar 16 dibawah ini:

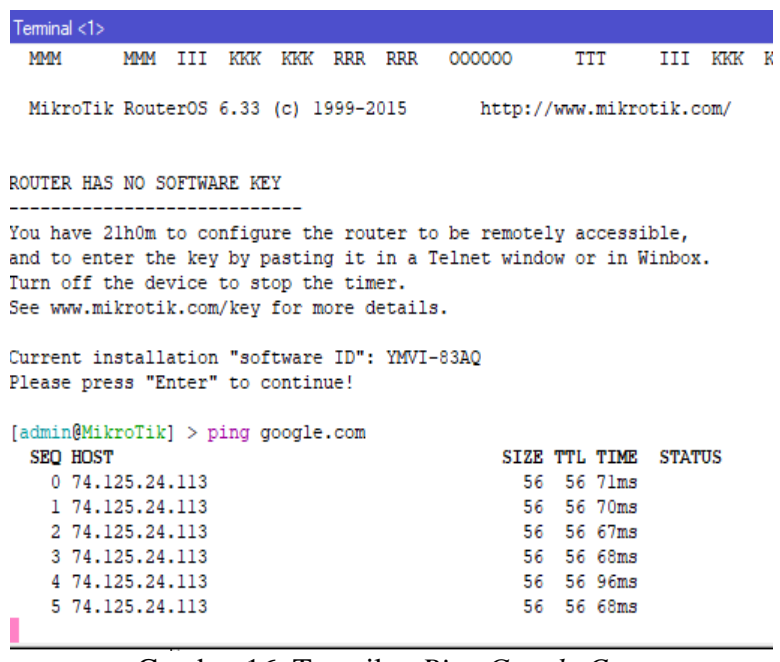

Gambar 16. Tampilan Ping Google.Com

Selanjutnya dilakukan proses untuk mengkonfigurasi manajemen bandwidth dan pemblokiran situs, seperti situs facebook, youtube, dll.

\section{Konfigurasi Manajemen Bandwidth Queue Tree Peer Connection}

Konfigurasi ini berjalan sesuai limit bandwidth yang digunakan. Konfigurasi ini dapat memberikan batas bandwidth berdasarkan IP Addresss, Port yang ada di mikrotik dan MAC Addresss. Dalam pengaturan limit bandwidth tahap pertama adalah dengan membuat Queue Type yang berguna untuk membagi bandwidth secara merata berdasarkan banyak user yang terhubung.

Konfigurasinya berupa Queue Type $P C Q$ dapat dilihat pada gambar 17 dibawah ini:

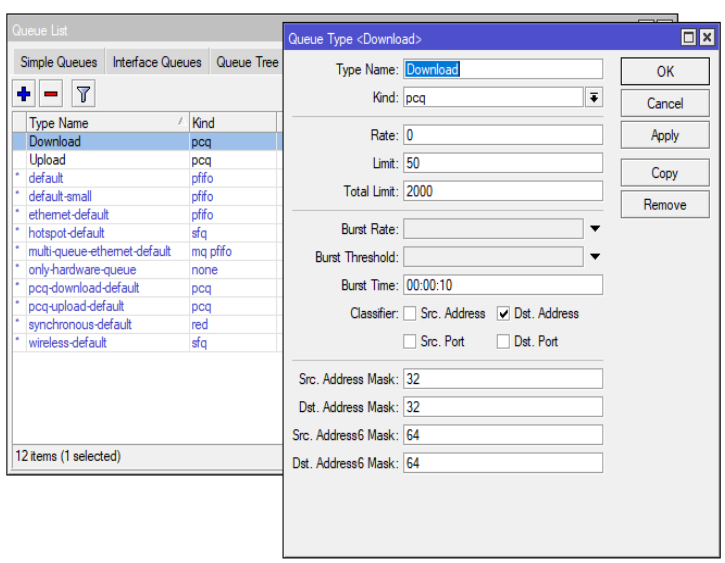

Gambar 17. Tampilan Queue Type PCQ Download
Konfigurasi Queue Tree selesai di Konfigurasi, selanjutnya dilakukan konfigurasi mangle. Konfigurasi mangle berfungsi untuk memanggil paket internet dan menentukan IP Address mana yang akan dilakukan proses limit. Dapat dilihat pada gambar 18 dibawah ini:

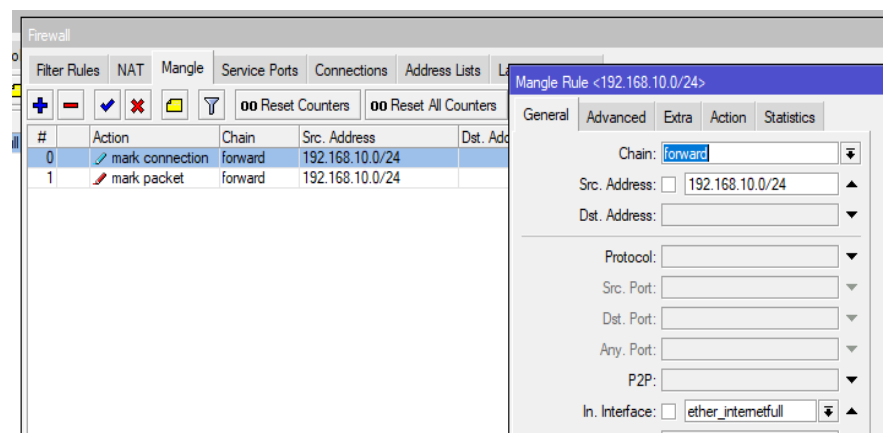

Gambar 18. Konfigurasi Mangle

Konfigurasi mangle sudah dilakukan selanjutnya konfigurasi Queue Tree, berfungsi dalam menentukan max limit bandwidth yang akan di buat. Dalam konfigurasi ini peneliti memberikan max limit sebesar upload 3Mbps dan download 3Mbps. Konfigurasi Queue Tree juga berpungsi untuk menentukan user prioritas, dimana peneliti membuat 8 untuk user prioritas. Dapat dilihat pada gambar 19 dibawah ini:

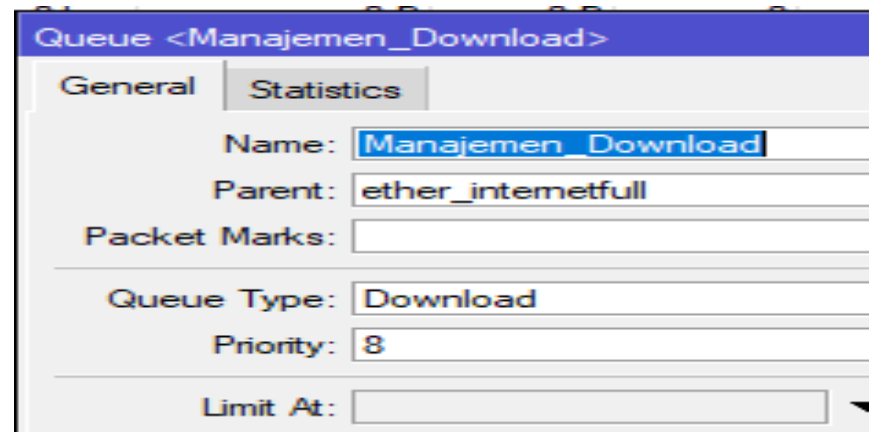

Gambar 19. Konfigurasi Queue Tree Menggunakan Kabel LAN

\section{Pengujian Sistem}

Pengujian sistem keamanan jaringan LAN Pada Dinas Lingkungan Hidup Pematangsiantar terdapat dua case yaitu: yang pertama dilakukan pengujian dengan menggunakan $H u b$, dan yang kedua pengujian dengan kabel $L A N$ terhubung langsung dengan laptop serta komputer.

\section{E. Pengujian Menggunakan Hub}

Pengujian ini dilakukan untuk mengetahui apakah hasil dari rancangan sesuai dengan kebutuhan.Pengujian menggunakan $\mathrm{Hub}$ dilakukan dengan cara Port dari Router Board Mikrotik yang kedua setelah selesai di konfigurasi dengan Program yang diinginkan dengan menghubungkan kabel $L A N$ ke Port Hub yang sudah disediakan. Setelah terhubung kemudian dilakukan pengujian dengan menghubungkan komputer dan laptop melalui $H u b$. Setelah Laptop dan komputer terhubung ke Hub jaringan Internet yang sudah termanajemen pun terhubung. Berikut gambar 20 manajemen Bandwidth Queue Tree dibawah ini: 


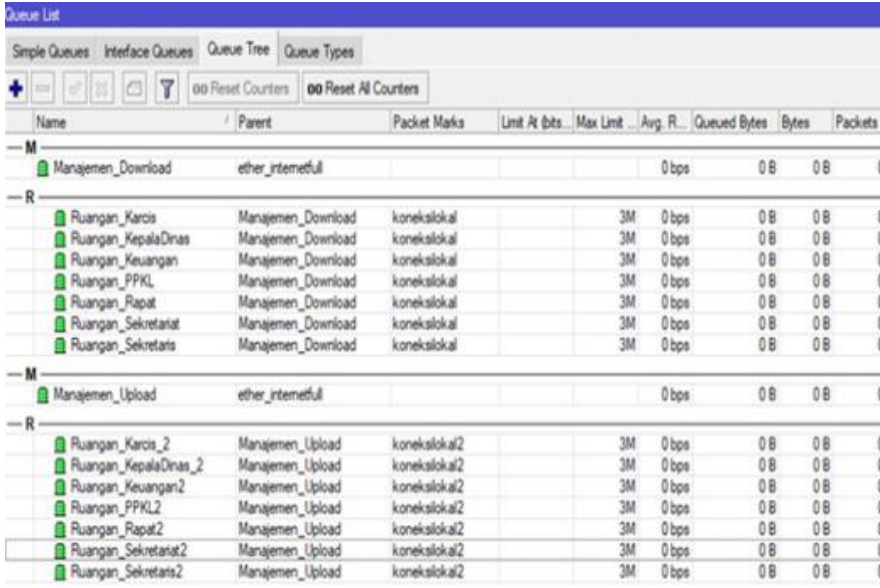

Gambar 20. Pengujian Manajemen Bandwidth

\section{F. Pengujian Menggunakan Laptop}

Pengujian menggunakan Laptop dilakukan dengan cara menghubungkan langsung kabel $L A N$ pada Laptop, Port 2 di mikrotik yang sudah di konfigurasi sehingga akses internet yang sudah tersusun dengan baik di hubungkan dengan kabel $L A N$ ke Port LAN laptop langsung point to point. Setelah terhubung pada laptop sehingga langsung dapat mengakses internet yang sudah di manajemen pada mikrotik.

\section{G. Hasil}

Berdasarkan pengujian diatas dapat disimpulkan bahwa hasil dari pengujian sistem diatas terbagi atas hasil dari manajemen bandwidth pada dinas lingkungan hidup pematangsiantar. Dimana hasil sudah sesuai dengan kebutuhan yang dirancang. Pengaturan bandwidth merupakan usaha untuk memberikan limit kuota internet bagi user dalam mengakses internet dengan kecepatan tertentu. Penerapan Bandwidth tersebut mempengaruhi kecepatan dalam proses upload dan kecepatan proses download yang diatur dengan baik sehingga dapat disesuaikan dengan keinginan user.

Hasil dari pengelolaan bandwidth bagi user dapat dilihat pada gambar 21 dibawah ini:

Uji kecepatan internet
Matensi: 189 md
Server: Singapore
Koneksi Internet Anda sangat lambat.
Kecepatan download Internet Anda sangat lambat.
Browsing web tidak akan bermasalah, tetapi proses
pemuatan video dapat berlangsung lama.

Gambar 21 Hasil Manajemen Bandwidth

\section{KESIMPULAN}

Dengan penggunaan perangkat wifi yang didukung oleh mikrotik memberikan kontribusi bagi upaya mengontrol batas volume internet (bandwidth), dimana adanya mikrotik lebih teratur dalam pengelolaan bandwidth maupun pengguna. pengawasan dan pengendalian pengguna dalam pengaksesan dan download menjadi lebih terkontrol. sehingga pegawai dapat menggunakan jaringan internet secara free yang aman dan terkontrol dengan baik. Berdasarkan pengujian yang dilakukan dapat disimpulkan bahwa hasil dari pengujian sistem terbagi atas hasil dari manajemen bandwidth pada dinas lingkungan hidup pematangsiantar. Dimana hasil sudah sesuai dengan kebutuhan yang dirancang. Pengaturan bandwidth memberikan limit kuota internet bagi user dalam mengakses internet dengan kecepatan tertentu. Penerapan Bandwidth tersebut mempengaruhi kecepatan dalam proses upload dan kecepatan proses download yang diatur dengan baik sehingga dapat disesuaikan dengan keinginan user.

\section{SARAN}

Sistem jaringan wifi yang dihasilkan hanya terfokus pada manajemen pembagian bandwidth dan manajemen download serta upload yang masih sederhana, bisa dikembangkan dengan metode lainnya.

\section{UCAPAN TERIMA KASIH}

Terima kasih kepada program studi Teknik Informatika, STIKOM Tunas Bangsa, Pematangsiantar dukungan dalam terlaksananya penelitian ini serta pembimbing yaitu Bapak Suhada dan Bapak M. Safii.

\section{REFERENSI}

[1] M. Ngafifi, "Kemajuan Teknologi Dan Pola Hidup Manusia Dalam Perspektif Sosial Budaya," J. Pembang. Pendidik. Fondasi dan Apl., vol. 2, no. 1, pp. 33-47, 2014, doi: 10.21831/jppfa.v2i1.2616.

[2] E. Febriyanti, S. Raharjo, and M. Sholeh, "Perbandingan Manajemen Bandwidth Menggunakan Metode FIFO (First In First Out) dan PCQ (Peer Connection Queue) Pada Router Mikrotik (Studi Kasus Pada Laboratorium Komputer Jaringan, Institut Sains \& Teknologi AKPRIND Yogyakarta)," J. JARKOM, vol. 5, no. 2, pp. 89-98, 2017.

[3] Y. Dimas, Y. Prasetyo, and L. Affandi, "MANAJEMEN BANDWIDTH UNTUK OPTIMALISASI JARINGAN di SMK TELKOM SANDHY PUTRA MALANG," J. Teknol. Inf., vol. 6, no. 1 , pp. 45-52, 2013.

[4] Mugiarso and Rasim, "PROXY SERVER SEBAGAI ALAT BANTU UNTUK MEMPERCEPAT AKSES INTERNET," SIGMAJurnal Teknol. Pelita Bangsa, vol. 6, no. 1, pp. 59-63, 2017.

[5] R. Hanifia, "Penerapan Quality of Service (Qos) Differentiated Service Pada Jaringan Multi-Protocol Label Switching (Mpls)," $J$. Manaj. Inform., vol. 9, no. 2, pp. 1-7, 2019.

[6] I. Faisal and A. Fauzi, "BANDWITH MENGGUNAKAN METODE QUEUE TREE dan PCQ ( PER CONNECTION QUEUEING )," $J$. Teknol. dan Ilmu Komput. Prima, vol. 1, no. 1, pp. 137-142, 2019.

[7] A. Nurdiyanto and Deli, "Studi Komparsi Managemen Bandwidth Antara Metode Hirarchical Token Bucket ( HTB ) Dan Peer Connection Queue ( PCQ )," Conf. Business, Soc. Sci. Innov. Technol., vol. 1, no. 1, pp. 487-497, 2020.

[8] M. A. S. Arifin, "Penerapan Bandwidth Management Untuk Dynamic User Pada Mikrotik Menggunakan Per Connection Queue (PCQ)," JATISI (Jurnal Tek. Inform. dan Sist. Informasi), vol. 4, no. 2, pp. 194-198, 2018.

[9] R. Kurniawan, "Analisis Dan Implementasi Desain Jaringan Hotspot Berbasis Mikrotik Menggunakan Metode NDLC (Network Development Life Cycle) Pada BPU Bagas Raya Lubuk Linggau," J. Ilm. Betrik, vol. 7, no. 01, pp. 50-59, 2016, doi: 10.36050/betrik.v7i01.12. 